\title{
PELATIHAN MANAJEMEN SDM DALAM MENINGKATKAN KUALITAS SUMBER DAYA MANUSIA (SDM) KARYAWAN DI UNIVERSITAS MALAHAYATI BANDAR LAMPUNG
}

\author{
Muhammad \\ Program Studi Manajemen, Fakultas Ekonomi, Universitas Malahayati \\ e-mail:muhammad@malahayati.com
}

\begin{abstract}
Abstrak
Kualitas SDM sangatlah penting untuk sebuah perusahaan agar dapat eksis dalam iklim persaingan dan ekonomi yang sedang lesu saat ini karena SDM juga merupakan modal dasar suatu perusahaan untuk mencapai tujuan perusahaan sehingga untuk menghasilkan SDM yang berkualitas, maka pendidikan dan pelatihan merupakan suatu hal yang penting dan untuk itu peningkatan kualitas SDM mutlak harus dilakukan, karena dengan kualitas SDM yang berkualitas dapat memberikan efek positif terhadap produktivitas kerja karyawan maupun perusahaan. Permasalahan yang ada pada karyawan adalah keterampilan yang dimiliki masih perlu ditingkatkan untuk menciptakan kesadaran mengenai pentingnya perencanaan dan manajemen sumber daya manusia. Masih rendahnya pengetahuan dan praktek tengatang MSDM dalam meningkatkan kinerja yang dilakukan. Tujuan kegiatan pengabdian kepada masyarakat ini adalah untuk memberikan pelatihan tentang Manajemen Sumber Daya Manusia secara sederhana kepada karyawan agar bisa menjalankan tugas dan tanggungjawab yang diberikan supaya terhindar dari penyalahgunaan weenang dalam menjalankan aktivitas sehari-hari. Manfaat dari kegiatan ini bagi karyawan adalah memberikan pengetahuan tentang cara merencanakan pengendalian, pelaksanaan, manajemen SDM, fungsi MSDM, dan cara melakukan pengendalian untuk meningkatkan kinerja. Metode yang digunakan dalam melaksanakan kegiatan ini adalah membuat rencana kegiatan pengabdian pada masyarakat yang meliputi tahap persiapan, perencanaan dan evaluasi. Diharapkan dengan adanya kegiatan pengabdian pada masyarakat ini bisa membatu karyawan dalam meningkatkan pemahaman dan motivasi tentang MSDM untuk membuat perencanaan agar kinerja bisa menjadi lebih baik dan optimal.
\end{abstract}

Kata kunci: Pelatihan, Manajemen SDM, Kualitas SDM, Karyawan.

\begin{abstract}
The quality of human resources is very important for a company to exist in a competitive climate and the current sluggish economy because human resources are also the basic capital of a company to achieve company goals so that to produce quality human resources, education and training is an important thing and to Therefore, improving the quality of human resources is absolutely necessary, because quality human resources can have a positive effect on the work productivity of employees and the company. The problem with employees is that their skills still need to be improved to create awareness about the importance of human resource planning and management. The knowledge and practice of HRM in improving the performance is still low. The purpose of this community service activity is to provide simple training on Human Resource Management to employees so that they can carry out their assigned duties and responsibilities in order to avoid abuse of authority in carrying out daily activities. The benefit of this activity for employees is to provide knowledge on how to plan control, implementation, HR management, HRM functions, and how to exercise control to improve performance. The method used in carrying out this activity is to make plans for community service activities which include the preparation, planning and evaluation stages. It is hoped that this community service activity can help employees increase understanding and motivation about HRM to make plans so that performance can be better and optimal.
\end{abstract}

Keywords: Training, HR Management, HR Quality, Employees. 


\section{PENDAHULUAN}

Di era persaingan global yang ketat, sumber daya manusia dianggap sebagai salah satu faktor yang paling penting memainkan peran utama dalam menjaga keberlanjutan organisasi, kredibilitas serta penciptaan kepercayaan publik. Penekanan pada sumber daya manusia sebagai modal berharga dalam organisasi mencerminkan tekanan lebih pada sumber daya tak berwujud daripada yang nyata. Investasi sumber daya manusia bertujuan untuk mendapatkan keuntungan bagi organisasi baik dalam jangka panjang atau pendek. Melalui keterampilan dan kemampuan yang dimiliki karyawan akan termotivasi untuk terus belajar membangun lingkungan bisnis yang unggul. Untuk mencapai tujuan perusahaan diperlukan kemampuan dalam memanfaatkan sumbersumber yang ada, sehingga mempunyai tingkat hasil dan daya guna yang tinggi.

Menurut Zainal (2015), peranan MSDM sangat menentukan terwujudnya tujuan perusahaan, karena untuk mengatur manusia tidak mudah maka perlu diatur dengan teori-teori manajemen yang memfokuskan mengenai pengaturan manusia (karyawan) dalam mewujudkan tujuan perusahaan/ organisasi. Adapun kegiatan manajemen SDM antara lain: melakukan analisis jabatan, merencanakan kebutuhan tenaga kerja dan merekrut calon pekerja, menyeleksi calon pekerja, memberikan insentif dan kesejahteraan, evaluasi kerja, mengkomunikasikan, memberikan penyuluhan, menegakkan disiplinan kerja, membangun komitmen kerja, memberikan keselamatan kerja, menyelesaikan perselisihan perburuhan, menyelesaikan keluhan dan relationship karyawan

Sumber daya manusia digunakan secara signifikan sebagai penggerak sumber daya lain dan memiliki posisi strategis yang berkontribusi untuk mewujudkan kinerja organisasi perusahaan dengan keunggulan kompetitif. Pengembangan sumber daya manusia memiliki hubungan langsung dengan profitabilitas organisasi. Oleh karena itu, setiap organisasi disarankan untuk mengoptimalkan kinerja karyawan dalam memberikan kontribusi yang optimal, antara lain dengan cara melakukan program pelatihan dan pengembangan (Effendi dan Sulistyorini, 2021).

Manajemen Sumber Daya Manusia diperlukan untuk meningkatkan efektivitas sumber daya manusia dalam sebuah organisasi. Tujuannya adalah memberikan kepada organisasi satuan kerja yang efektif. Untuk mencapai tujuan ini, studi tentang manajemen personalia akan menunjukkan bagaimana seharusnya perusahaan mendapatkan, mengembangkan, menggunakan, mengevaluasi, dan memelihara karyawan dalam jumlah (kuantitas) dan tipe (kualitas) yang tepat (Istiantara, 2019).

Kualitas SDM sangatlah penting untuk sebuah perusahaan agar dapat eksis dalam iklim persaingan dan ekonomi yang sedang lesu saat ini karena SDM juga merupakan modal dasar suatu perusahaan untuk mencapai tujuan perusahaan sehingga untuk menghasilkan SDM yang berkualitas, maka pendidikan dan pelatihan merupakan suatu hal yang penting dan untuk itu peningkatan kualitas SDM mutlak harus dilakukan, karena dengan kualitas SDM yang berkualitas dapat memberikan efek positif terhadap produktivitas kerja karyawan maupun perusahaan.

Kualitas SDM (karyawan) mengacu pada:

1. Pengetahuan (knowledge) yaitu penguasaan ilmu dan teknologi yang diperoleh melalui proses pembelajaran serta pengalaman

2. Keterampilan (skill) untuk memanipulasi suatu objek secara fisik.

3. Kemampuan (abilities) yaitu sikap untuk mengerjakan tugas dalam berwirausaha juga mempengaruhi kualitas suatu SDM (Hilda dan Elly, 2019).

Peningkatan kinerja sumber daya manusia secara umum dapat dilakukan dengan peningkatan koordinasi dan kerja sama tim antar seksi dan antar karyawan dalam menyatukan visi dan misi perusahaan secara professional yang didasarkan pada prinsip. SDM dapat menjadi andalan dalam memberikan service pelayanan yang baik. Layanan tersebut dapat memberikan informasi yang diperlukan oleh mahasiswa, dosen atau pihak-pihak lain yang memerlukannya setiap waktu dengan baik dan efektif.

Peningkatan kinerja karyawan akan membawa kemajuan bagi perusahaan atau organisasi untuk dapat bertahan dalam suatu persaingan lingkungan dunia kerja yang tidak stabil. Oleh karena itu upaya-upaya untuk meningkatkan kinerja pegawai merupakan tantangan manajemen yang paling serius karena keberhasilan untuk mencapai tujuan dan kelangsungan hidup organisasi, institusi tergantung pada kualitas kinerja sumber daya manusia yang ada didalamnya.

Sumber daya manusia yang bermutu makin dibutuhkan sejalan dengan kemajuan ilmu pengetahuan dan teknologi (iptek) yang makin masif akhir-akhir ini. Kecenderungan ini 
berimplikasi pada perlunya aktualitas wacana pengembangan sumber daya manusia dalam keragaman bentuk investasi (Fitri, 2019).

Kegiatan Pengabdian Kepada Masyarakat yang dilakukan dalam bentuk pelatihan tentang kualitas sumber daya manusia kepada karyawan di Universitas Malahayati Bandar Lampung. Target kegiatan ini adalah menghasilkan sumber daya yang bisa dan mampu untuk meningkatkan ilmu pengetahuan tentang cara menjalankan tugas yang telah diberikan, yang meliputi ilmu pengetahuan tentang perencanaan pengeluaran keuangan keluarga, ilmu pengetahuan tentang pelaksanaan manajemen keuangan keluarga, dan ilmu pengetahuan tentang penilaian/ pengawasan keuangan keluarga.

Tujuan kegiatan pengabdian kepada masyarakat ini adalah untuk memberikan pelatihan tentang Manajemen Sumber Daya Manusia secara sederhana kepada karyawan agar bisa menjalankan tugas dan tanggungjawab yang diberikan supaya terhindar dari penyalahgunaan weenang dalam menjalankan aktivitas sehari-hari. Manfaat dari kegiatan ini bagi karyawan adalah memberikan pengetahuan tentang cara merencanakan pengendalian, pelaksanaan, manajemen SDM, fungsi MSDM, dan cara melakukan pengendalian untuk meningkatkan kinerja.

Berdasarkan gambaran diatas, maka dapat diambil beberapa permasalahan yang ada pada karyawan adalah keterampilan yang dimiliki masih perlu ditingkatkan untuk menciptakan kesadaran mengenai pentingnya perencanaan dan manajemen sumber daya manusia. Masih rendahnya pengetahuan dan praktek tengatang MSDM dalam meningkatkan kinerja yang dilakukan.

Setelah mengikuti pelatihan ini, semua peserta akan memiliki kesadaran, pola fikir dan pola sikap hidup yang konstruktif terutama dalam hal pemanfaatan peluang dan kesempatan, serta mampu menerapkannya sesuai dengan ketentuan yang sudah ada.

\section{METODE}

Kegiatan telah dilaksanakan pada hari Jumat, 05 Februari 2021 Pukul 09.00 hingga selesai. Subjek dalam pengabdian ini adalah karyawan yang dilaksanakan secara virtual (Room Zoom Meeting). Sistem daring saat ini umumnya digunakan untuk seminar atau kursus pelatihan yang diadakan melalui internet, baik dengan biaya atau gratis. Oleh karena itu, partisipasi tidak terbatas pada lokasi tetap, tetapi membutuhkan akses internet (Gunawan et al, 2020). Kegiatan dilakukan dengan memberikan edukasi berupa pelatihan dengan beberapa tahapan sebagai berikut:

1. Materi

Penyampaian materi oleh narasumber sesuai dengan tema yang telah di tentukan berdasarkan bidang kelimuan yang telah ditekuni. Hal ini disebabkan karena masih ada beberapa permasalahan dilihat dari gaya kepemimpinan berorientasi tugas, berorientasi hubungan, dan kinerja karyawan selama tahun berjalan.
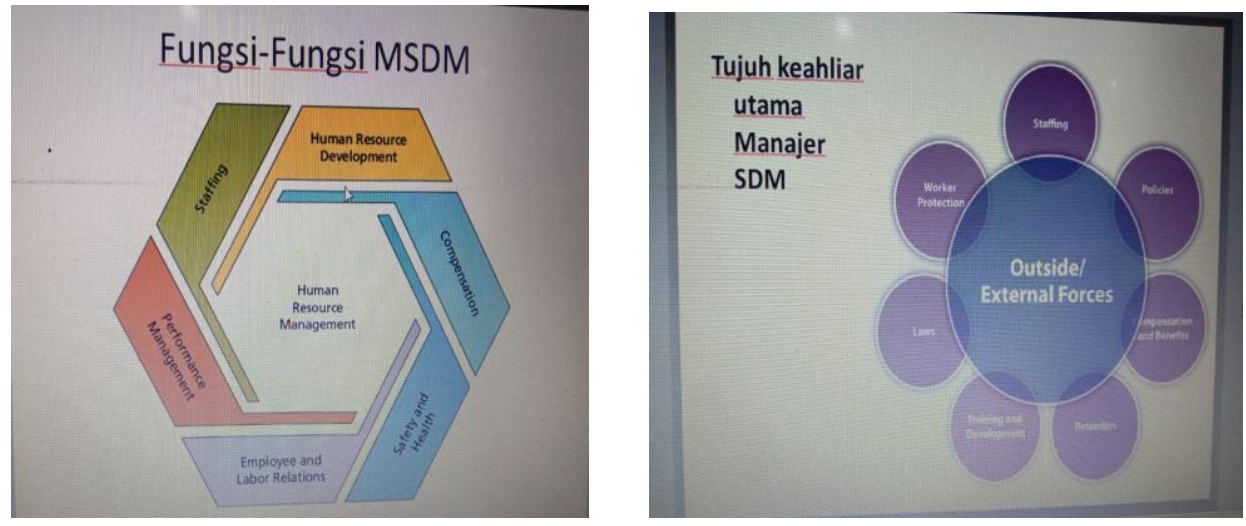

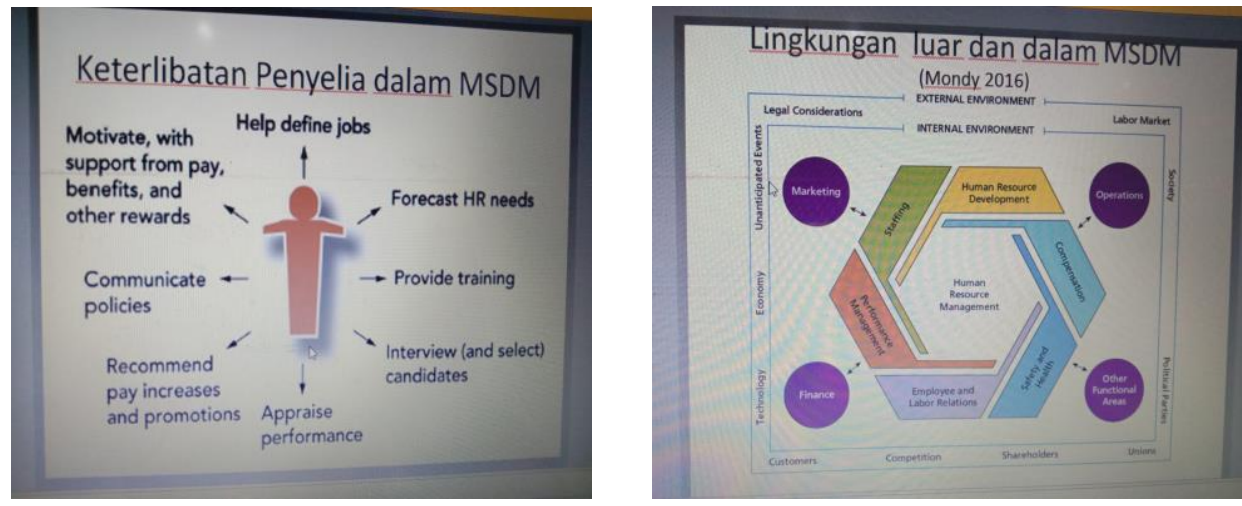

Gambar 1. Materi Pelatihan Manajemen Sumber Daya Manusia

2. Pelaksanaan

a. Tahap Penyusunan Materi

Narasumber diberikan waktu satu minggu untuk menyiapkan materi presentasi dengan memperhatikan beberapa aspek seperti: jumlah slide dan kesesuaian isi agar materi dapat tersampaikan dan diterima dengan baik.

b. Tahap pelaksanaan

Pada tahap pelaksanaan, panitia (host) membuka platform zoom 30 menit sebelum acara berlangsung. Host pelatihan daring adalah Universitas Malahayati dan disiarkan langsung melalui room zoom meeting. Akses masuk room zoom meeting peserta diberikan oleh host satu hari sebelum kegiatan berlangsung. Peserta diberikan kuisioner daring menggunakan platform google-form untuk menggali data terkait pengembangan MSDM.

Peserta pelatihan berikutnya diberikan penjelasan tentang Manajemen Sumber Daya Manusia, kemudian peserta dilatih untuk membuat perencanaan kinerja dengan template atau lembar kerja yang sudah disediakan, sehingga mempermudah dalam penerapan dan pada akhirnya mampu menghasilkan perencanaan kinerja yang matang dan baik. Rancangan kegiatan pengabdian masyarakat menjadi tiga tahap yaitu:

Table 1.

Rencana Kegiatan Pengabdian pada Masyarakat

\begin{tabular}{|c|c|c|}
\hline NO & TAHAPAN KEGIATAN & URAIAN TUGAS \\
\hline 1 & Persiapan & $\begin{array}{l}\text { a. Persiapan kelengkapan administrasi; } \\
\text { surat menyurat, surat izin, bahan, materi. } \\
\text { b. Persiapan media dan fasilitas penunjang } \\
\text { c. Persiapan undangan peserta, power } \\
\text { point, penyusunan template, modul } \\
\text { materi. } \\
\text { 1. Persiapan pengurusan surat tugas, } \\
\text { surat izin melakukan kegiatan dan } \\
\text { materi. } \\
\text { 2. LCD Projector, Laptop, Template } \\
\text { (Lembar Kerja). } \\
\text { 3. Lembar Undangan peserta } \\
\text { d. Persiapan panitia pengabdian } \\
\text { masyarakat tangang dan tanggung } \\
\text { 1. Pembagian tugas jawab. } \\
\text { e. Metode: } \\
\text { 1. Studi Literatur } \\
\text { 2. Diskusi } \\
\text { f. Penetapan Lokasi Pelatihan, pelatihan }\end{array}$ \\
\hline
\end{tabular}




\begin{tabular}{|c|c|c|}
\hline & & $\begin{array}{l}\text { dilakukan di secara virtual (Room Zoom } \\
\text { Meeting). }\end{array}$ \\
\hline \multirow[t]{12}{*}{2} & \multirow{12}{*}{ Pelaksanaan } & \multirow{12}{*}{$\begin{array}{l}\text { Penyampaian materi: } \\
\text { a. Pembukaan } \\
\text { b. Penyampaian materi } \\
\text { 1. Penjelasan pentingnya MSDM } \\
\text { dalam organisasi. } \\
\text { 2. Pengertian MSDM. } \\
\text { 3. Ruang lingkup MSDM } \\
\text { 4. Fungsi MSDM } \\
\text { 5. Perencanaan Sumber Daya Manusia } \\
\text { 6. Pengembangan Sumber Daya } \\
\text { Manusia } \\
\text { c. Metode: } \\
\text { Diskusi, Ceramah, Workshop dan Tanya } \\
\text { jawab. }\end{array}$} \\
\hline & & \\
\hline & & \\
\hline & & \\
\hline & & \\
\hline & & \\
\hline & & \\
\hline & & \\
\hline & & \\
\hline & & \\
\hline & & \\
\hline & & \\
\hline 3 & Evaluasi & $\begin{array}{l}\text { a. Diskusi dan Tanya jawab. } \\
\text { b. Evaluasi hasil pelatihan. }\end{array}$ \\
\hline
\end{tabular}

\section{HASIL DAN PEMBAHASAN}

Kegiatan pengabdian masyarakat ini diselenggarakan oleh universitas Malahayati Bandar Lampung . Peserta dalam kegiatan ini adalah karyawan yang berada dilingkungan Universitas Malahayati. Pelatihan dilaksanakan selama 1 hari pada tanggal 05 Februari 2021 yang bertempat room zoom meeting. Setelah pelatihan dilakukan, pendampingan tetap diberikan selama 1 minggu.

Peserta yang menghadiri kegiatan pelatihan tersebut merupakan karyawan yang sudah bekerja di lingkungan Universitas Malahayati. Sehingga ketika pelaksanaan pelatihan seluruh peserta dapat mengikuti acara sampai dengan selesai. Narasumber dalam pelatihan ini adalah Muhammad, S.Kom., M.M.

Kegiatan Pengabdian ini akan dievaluasi melalui pemberian kertas kerja dengan cara melakukan pengawasan terhadap kinerja dengan tujuan untuk mengetahui peningkatan pengetahuan tentang perencanaan. Pelaksanaan kegiatan Pengabdian pada Masyarakat ini dilakukan dengan menggunakan metode ceramah, tutorial, dan diskusi. .Adapun hasil kegiatan pengabdian masyarakat ini adalah karyawan dapat memahami pentingnya Manajemen Sumber Daya Manusia dalam orgnisasi. Disamping itu karyawan dapat mempraktekkan mengenai perencanaan dalam MSDM di lingkungan kerja.

Pelatihan yang sudah berjalan dengan lancar akan mewujudkan suatu administrasi yang baik dan memiliki menfaat yang sangat berarti karena bisa menambah pengetahuan dan wawasan peserta mengenai MSDM. Ada perencanaan kegiatan, pelaksanaan dan monitoring serta komunikasi mengenai evaluasi hasil kegiatan. Hal yang penting adalah kegiatan tersebut harus terdokumentasi dengan baik disertai dengan adanya berita acara pada setiap kegiatan. Tetapi perlu dilakukan pendampingan lanjutan untuk melatih agar karyawan bisa lebih baik serta konsisten dalam melakukan tugas dan tanggungjawabnya dalam menjalankan aktivitas untuk mencapai tujuan organisasi. Berikut dokumentasi pelaksanaan kegiatan. 


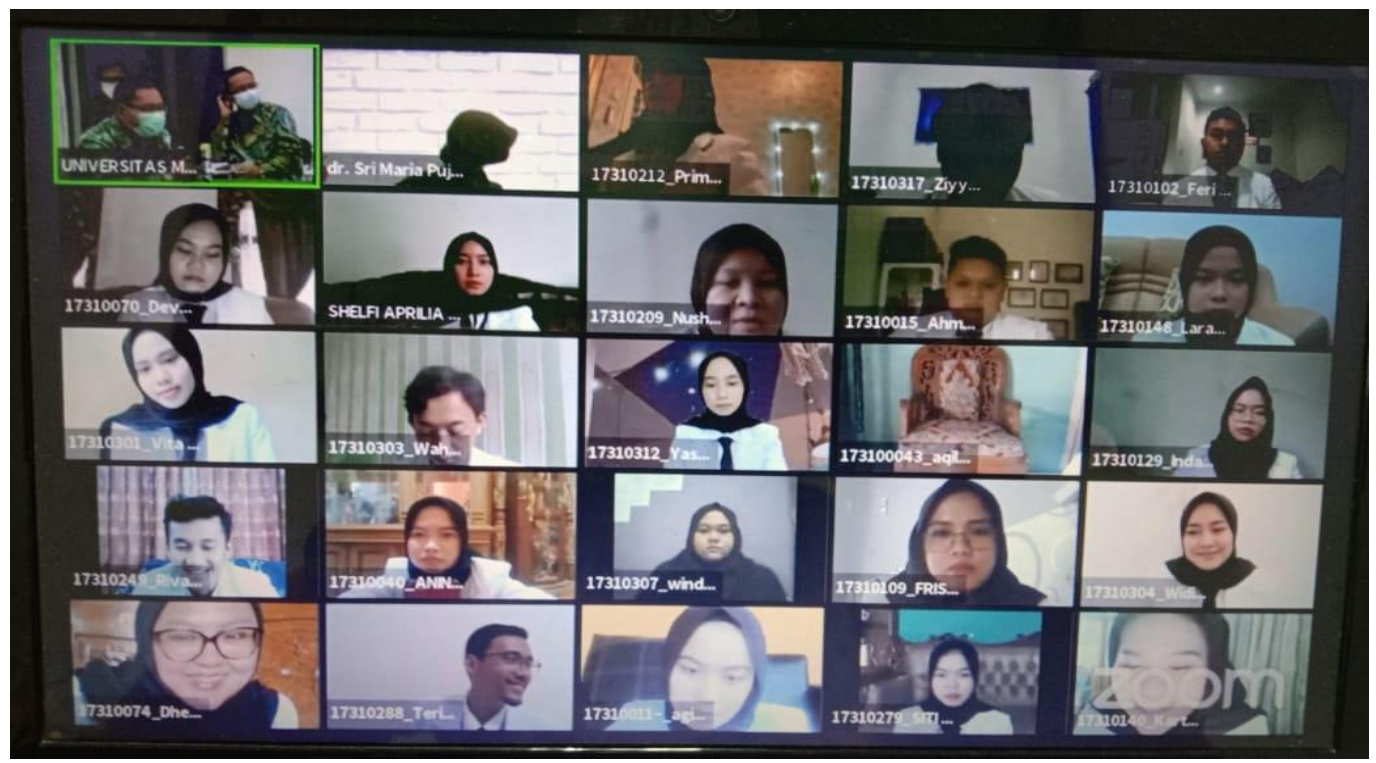

Gambar 2. Pelaksanaan Pelatihan Manajemen SDM secara daring pada zoom meeting

Peserta pelatihan cukup antusias terbukti dengan adanya feedback dari karyawan dengan aktif memberikan pertanyaan dan sanggahan terkait materi. Materi pelatihan dapat diterima dengan baik, terbukti dengan sebelum materi disampaikan tingkat pengetahuan peserta tentang MSDM sebesar (20\%), sedangkan setelah materi disampaikan kemampuan peserta untuk menjawab pertanyaan dan memahami materi yang disampaikan meningkat menjadi $80 \%$. Pelaksanaan kegiatan pengabdian kepada masyarakat dirasa memiliki menfaat yang sangat berarti dan berguna dalam memberikan pemahaman ilmu pengetahuan yang pada akhirnya dapat diimplementasikan di lingkungan kerja

\section{SIMPULAN}

Berdasarkan hasil dan pembahasan yang sudah disampaikan pada pelaksanaan pengabdian masyarakat mengenai pelatihan Manajemen Sumber Daya Manusia yang ditujukan pada karyawan yang telah diuraikan sebelumnya, dapat diambi kesimpulan sebagai berikut:

1. Meningkatnya pemahaman karyawan setelah mengikuti pelatihan, peserta mampu membuat perencanaan yang bermanfaat dalam menjalankan tugas dan tanggungjawabnya.

2. Mampu meningkatkan kesadaran peserta pelatihan tentang pentingnya Manajemen Sumber Daya Manusia setelah mengikuti pelatihan.

3. Meningkatnya motivasi peserta pelatihan untuk melakukan pembuatan perencanaan untuk meningkatkan kinerja.

\section{SARAN}

Kegiatan pengabdian pada masyarakat MSDM dilakukan dengan waktu yang singkat, karena untuk memahami MSDM harus memiliki waktu yang cukup agar para karyawan bisa memahami sepenuh ya tentang MSDM. Namun ternyata telah memberikan dampak yang luas terhadap motivasi karyawan. Kedepan sangat diharapkan agar perguruan tinggi bisa bekerjasama dengan mitra dari dunia usaha agar dapat melaksanakan kegiatan pengabdian pada masyarakat dalam waktu yang lebih lama dengan peserta lebih banyak lagi.

\section{UCAPAN TERIMA KASIH}

Ucapan Terima kasih tak terhingga kepada Tim Pengabdian pada masyarakat Universita Malahayati Bandar Lampung, Kepala Kepegawaian, karyawan, dan semua civitas yang sudah memfasilitasi dan memberi dukungan penuh dalam melaksanakan kegiatan Pengabdian kepada Masyarakat $(\mathrm{PkM})$ ini. 


\section{DAFTAR PUSTAKA}

Effendi dan Sulistyorini. (2021). Pengembangan Sumber Daya Manusia Di Lembaga Pendidikan Islam. Tajdidukasi: Jurnal Penelitian Dan Kajian Pendidikan Islam, 2(1), 39-51. https://doi.org/10.47736/tajdidukasi.v8i1.303

Fitri. (2019). Pendampingan Pengembangan Sumber Daya Manusia dalam Organisasi Remaja Masjid. Janaka, Jurnal Pengabdian Masyarakat, 1(2), 82-83. http://ejournal.staidakrempyang.ac.id/index.php/janaka/article/view/173

Gunawan et al. (2020). Webinar sebagai Sumber Belajar di Tengah Pandemi Covid-19. Purwadinata: Jurnal Agama Dan Budaya, 4(2), 127-132.

Hilda dan Elly. (2019). Peningkatan Kualitas Sumber Daya Manusia untuk Pengembangan Sistem Informasi Geospasial. Jurnal SOLMA, 8(2), 258-267. https://doi.org/10.29405/solma.v8i1.3126

Istiantara. (2019). Pengembangan Manajemen Sumber Daya Manusia Berbasis Kompeteni Guna Meningkatkan Kinerja Pegawai dan Dosen Politeknik Perkeretaapian Indonesia. Jurnal Perkeretaapian Indonesia, III(2), 93 - 101.

Veithzal Rivai Zainal . (2015). Manajemen Sumber Daya Manusia Untuk Perusahaan . Edisike-7. Depok: PT RAJAGRAFINDO. 